\title{
Metal uptake and sequestration within Southern Ocean diatom frustules: A significant sink for iron and zinc
}

\author{
ERIN CASTORINA ${ }^{1}$, Ellery D. INGALL ${ }^{1}$, PETER L. \\ MORTON $^{2}$, LESLEY A. BREWER ${ }^{1}$, MARY F. M. \\ MCDANIEL $^{1}$ AND BARRY LAI ${ }^{3}$ \\ ${ }^{1}$ School of Earth and Atmospheric Sciences, Georgia \\ Institute of Technology, 311 Ferst Dr NW, Atlanta, GA, \\ 30318, USA \\ ${ }^{2}$ National High Magnetic Field Laboratory, 1800 E Paul \\ Dirac Dr, Tallahassee, FL, 32306-4520, USA \\ ${ }^{3}$ Advanced Photon Source, Argonne National Laboratory, \\ 9700 S. Cass Avenue, Argonne, IL, 60439, USA
}

Diatoms, abundant and productive microbes present in all the Earth's seas, account for approximately $43 \%$ of annual global marine carbon sequestration. Data from three cruises in the Southern Ocean reveals substantial uptake of iron (Fe) and zinc $(\mathrm{Zn})$ into the diatom's silicate exoskeleton, or frustule. Iron is a necessary nutrient with proven limitations on diatom productivity. Zinc is a critical element in some enzymes necessary for the growth of the diatom. Yet in the Southern Ocean, dissolved $\mathrm{Fe}$ and $\mathrm{Zn}$ concentrations are extremely limited. Hence, $\mathrm{Fe}$ and $\mathrm{Zn}$ availability act to limit primary productivity. Using the synchrotron at Argonne National Laboratory, the elemental concentrations of silicon ( $\mathrm{Si}), \mathrm{Fe}$ and $\mathrm{Zn}$ in diatoms have been investigated using X-ray micro-fluorescence at a $300 \mathrm{~nm}$ resolution. An analysis of 300 diatoms from an extensive sample collection along the $67^{\circ} \mathrm{S}$ transect in the Pacific sector of the Southern Ocean, indicates a molar uptake ratio of $380 \mu \mathrm{mol} \mathrm{Zn:mol} \mathrm{Si} \mathrm{and} \mathrm{a} \mathrm{median}$ value of $45 \mu \mathrm{mol} \mathrm{Fe:mol} \mathrm{Si.} \mathrm{X-ray} \mathrm{absorption} \mathrm{near-edge}$ structure (XANES) spectroscopy on a subset of these samples illustrates that $\mathrm{Zn}$ is bound to the silica frustule in $80 \%$ of the samples and preliminary data indicate that $\mathrm{Fe}$ occurs within the frustule as reduced $\mathrm{Fe}(\mathrm{II})$.

XANES spectral data, strong correlations between the $\mathrm{Fe}: \mathrm{Si}$ and $\mathrm{Zn}: \mathrm{Si}$ ratios, and results from chemical treatments of frustules indicate that these metals are incorporated into the silicate structure of the frustule, rather than existing as a collocated element or a surface coating. The frustule, relative to the labile organic cellular material, will achieve greater vertical transport prior to remineralization and will sink more quickly into the intermediate and bottom waters. These complementary mechanisms move the incorporated $\mathrm{Fe}$ and $\mathrm{Zn}$ into deeper waters and create global implications for the potential loss of these trace minerals from the surface ocean. 